\title{
Book Review: Fundamentals of Soil Ecology (Third Edition)
}

\author{
Maria J. I. Briones* \\ Departamento de Ecología y Biología Animal, Universidad de Vigo, Vigo, Spain \\ Keywords: soil ecology, terrestrial ecosystems, soils, microbes, soil invertebrates
}

A Book Review on

Fundamentals of Soil Ecology (Third Edition)

David Coleman, Mac Callaham and D. Crossley, Jr., (London: Academic Press), 2017, 376 pages, ISBN: 9780128052518, and cover page given in Figure 1.

When a third edition of a book is published, that generally means that the first two editions were successful and attracted quite a bit of attention. This book by Coleman et al. (2017) is no exception in this respect. Since the second edition was published, in 2004, many advances have been made in terms of new methodologies, detailed knowledge concerning a wide range of organisms, identifying outstanding challenges, and delineating future research needs in soil ecology. Indeed, technological advances have allowed us to increase the resolution of soil analyses, speed up sample processing, and scale down measurements to the molecular level to improve taxonomic identifications. All these improvements have been compiled in the third edition of the book in the form of updated phylogenies, electron scanning microphotographs, and conceptual diagrams and models. The book also reflects the fact that what we understand by the still somewhat obscure expression of "soil ecology" continues to evolve. At about the time the second edition was published, 14 years ago, plant ecologists and soil ecologists started to realize that a full assessment of soil processes required the inclusion of plant-soil interactions (e.g., Wardle et al., 2004). Over the subsequent years, soil ecology evolved into a multidisciplinary field linking above- and belowground components (soil, plants, microbes, and invertebrates), their activities (growth, metabolic, and mobility rates) and their spatio-temporal changes to soil processes. For all these reasons, a third edition of Fundamentals of Soil Ecology is absolutely timely.

This edition too is aimed at both students and ecosystem researchers. The general structure of the book follows the same basic (hierarchical) format as the previous editions, starting with overviews of the different components of the soil systems (plants in Chapter 2 and belowground biota in Chapters 3 and 4), followed by descriptions of decomposition processes (Chapter 5), soil food webs (Chapter 6), linkages between soil biodiversity and soil processes (Chapter 7), and ways forward in soil ecology research (Chapter 8). The final chapter of the book (Chapter 9) offers a series of practical exercises to study root, microbial, and faunal dynamics.

In the introductory section of the book (1.2 The Historical Background of Soil Ecology), the authors remind readers that the name of "Adam" ("first man created") is derived from the Hebrew word for soil, "adama." From the onset, therefore, the authors insist on the close connections that link human experience with soils. This leads to a discussion of the fact that soils have always been considered as a "fundamental element" by early civilisations. A classic theory of four equal and commensurate elements was formulated by Empedokles and adopted by Plato and Aristotle. They 
pointed out that "Earth, air, fire, and water do not only exist in recognizable isolation but also are constantly combined in nature by mixing into innumerable inorganic and organic compounds, giving the basis for substances and beings that came to be summarily classified as mineral, plant, animal, and man. The order is hierarchical with mineral having only one element (earth) and man having all four" (Benson, 2000).

In spite of this long-standing association of "soils" with human activities, the term of "soil" means different things to different people (pedologists, agronomists, botanists, zoologists, engineers, farmers, gardeners, etc.). Architects, engineers, and astronomers use the term to refer to unconsolidated granular material supporting buildings, infrastructures, or occurring at the surface of other planets, but the practice is frowned upon by quite a few soil scientists. Without necessarily delving into the on-going debate on the topic, Coleman et al. (2017) have attempted, judiciously, to define precisely what they meant by "soil" in the context of their book. In the first chapter, the authors define soils strictly in the context of the fundamental equation of soil forming factors developed by Jenny (1941). His equation clearly illustrates that soils are more complex than just the one element as hypothesized by Greek philosophers, and that the "mineral element," which could be assimilated to "parent material" in Jenny's equation, should be called "soil" only after interacting with four other independent environmental factors: climate, topography, soil organisms, and time. This means that, from a soil formation perspective, soils are alive, sensitive to various environmental drivers, and susceptible to aging.

After the introductory chapter, the book dedicates Chapter 2 to the rhizosphere (roots and associated processes). As the authors point out correctly, the fact that early research did not attempt to account for this important component of plant productivity is usually associated with difficulties encountered when trying to obtain accurate measures of root biomass. The section 2 of this chapter provides a good overview of the different methodologies that have been used in the literature, from destructive methods (soil washing, sieving, sorting, and drying), tracer (isotope ${ }^{14} \mathrm{C} /{ }^{12} \mathrm{C}$ dilution) and root-ingrowth studies (in situ incubations of mesh bags containing root-free soil), to direct observations through glass windows of growing roots (in rhizotrons and minirhizotrons). Each of these methods has advantages and disadvantages in terms of being tedious and timeconsuming, and because of the sometimes questionable quality of data produced, e.g., in the case of estimation errors resulting from not taking root morphology and spatial distribution into account, or from root age, which could be markedly different at different soil depths as well as across ecosystems and land use managements.

The third chapter of the book is dedicated to microorganisms, in particular their diversity, the methods to estimate their abundance/biomass, the processes they regulate, and the models that have been proposed to describe their interrelationships with roots, soil aggregates, soil processes, and ecosystem dynamics. It is astonishing to discover that, after so much progress in microbial ecology, we are still unable to provide an accurate estimate of how many different "microbial entities" (virus, archaea, bacteria, fungi, protozoa) and species of each of these groups can be found in soils. More than $97 \%$ of fungal species present in soils are still awaiting to be discovered and named (Hawksworth and Lücking, 2017). And this lack of knowledge persists despite the current advances in molecular techniques (DNA and RNA sequencing, proteomics, metabolomics, isotope probing, PLFAs, etc.). Other lingering "old problems," such as insufficient culturing methods and primers, also limit our ability to accurately identify, let alone simply sample, the vast variety of microorganisms that are assumed to live in the soils of many ecosystems.

The vast array of different invertebrates inhabiting soils (also exhibiting an enormous variability in size, life cycles, feeding preferences, activities, and involvement in soil processes) constitutes the core of Chapter 4 of the book. Knowing how many different soil faunal organisms live in our soils (in terms of species diversity, abundances, and population dynamics) as well as their trophic relationships (covered in Chapter 6 of the book) is crucial to understand why this huge biodiversity is needed and to link their activities to soil processes (Chapter 7).

Soil organic matter decomposition, through which dead plant materials (litter, roots) are broken down into smaller particles and organic substances that are progressively mineralized, along with nutrient cycling, requires the action of soil organisms, from the smallest microorganisms (e.g., bacteria, archaea, fungi, protists) to the largest soil invertebrates (e.g., earthworms and ants). The decomposing activities of these organisms are controlled by several factors, including physical (temperature and moisture) and chemical conditions (soil acidity, resource quality). Defining the roles of the different biotic players and environmental factors have on the decomposition rates has guided the research on this topic during the last decades (Cotrufo et al., 2010). This explains the elevated number of publications with the terms "decomposition" and "soil" that can be found in the Web of Science, and this number continues to grow at a very fast pace (19,000 in March 2017 according to the book; 41,290 when I last accessed it in May 2018). If we aim to better summarize the integrating ecosystem properties into mathematical models, our future research work should, as the authors wisely conclude in Chapter 5, "pay more attention to the details, yet considering them in a holistic perspective" (p. 211).

After exploring the structure and activities of the primary producers and heterotrophic organisms (Chapters 2, 3, and 4) and their interrelationships and linkages to soil processes (Chapters 5, 6, and 7), the authors describe several areas of interest which are rapidly changing and that would allow us to scale up (global perspective) our understanding of soil ecology (Chapter 8). As primary fields that are in dire need for further research, the authors place their first focus on the importance of gaining a better understanding of the role of soils in $\mathrm{C}$ sequestration (section 8.2), in the global C cycle (section 8.3), and when modeling $C$ dynamics (section 8.4). Another challenge in soil ecology research, according to the authors, is our failure to consider multifactor interactions, in particular when investigating the effects of global change (section 8.5). For example, changes in ecosystem functions (e.g., as a result of plant community structure) could alter the resource provisioning (quantity and quality) to the below-ground communities and in 
turn, the consumption rates of the decomposers, with potential feedbacks to global change.

However, not only should researchers avoid to consider the interactions among different global drivers (climatic, GHG, N deposition, land use, species invasions), but also the different levels of organization in an ecosystem (individual, population, community, ecosystem, biome, and biosphere), the ecological traits of different organisms, and the top-down and bottom-up interactions (i.e., direct and indirect relationships between plants, soil organisms, and resources) should be investigated (Briones, 2014). If soils function as a "superorganism" (like in the Gaia theory mentioned in section 8.7 of the book), whose components have all co-evolved together and are able of self-regulation to keep conditions optimal for persistence, we need to know what is the minimum number of soil properties (abiotic and biotic) that should remain invariant to assure its good functioning, and which soil processes could counteract any unfavorable conditions that could emerge.

To encourage students and young researchers to enter the fascinating world of soil ecology, it is extremely useful to provide them with several methodological approaches to not only see the different components of soil systems (roots, mycorrhizae, micro-, meso- and macro-fauna), but also their activities (e.g., soil respiration). Compared to the previous edition, this section

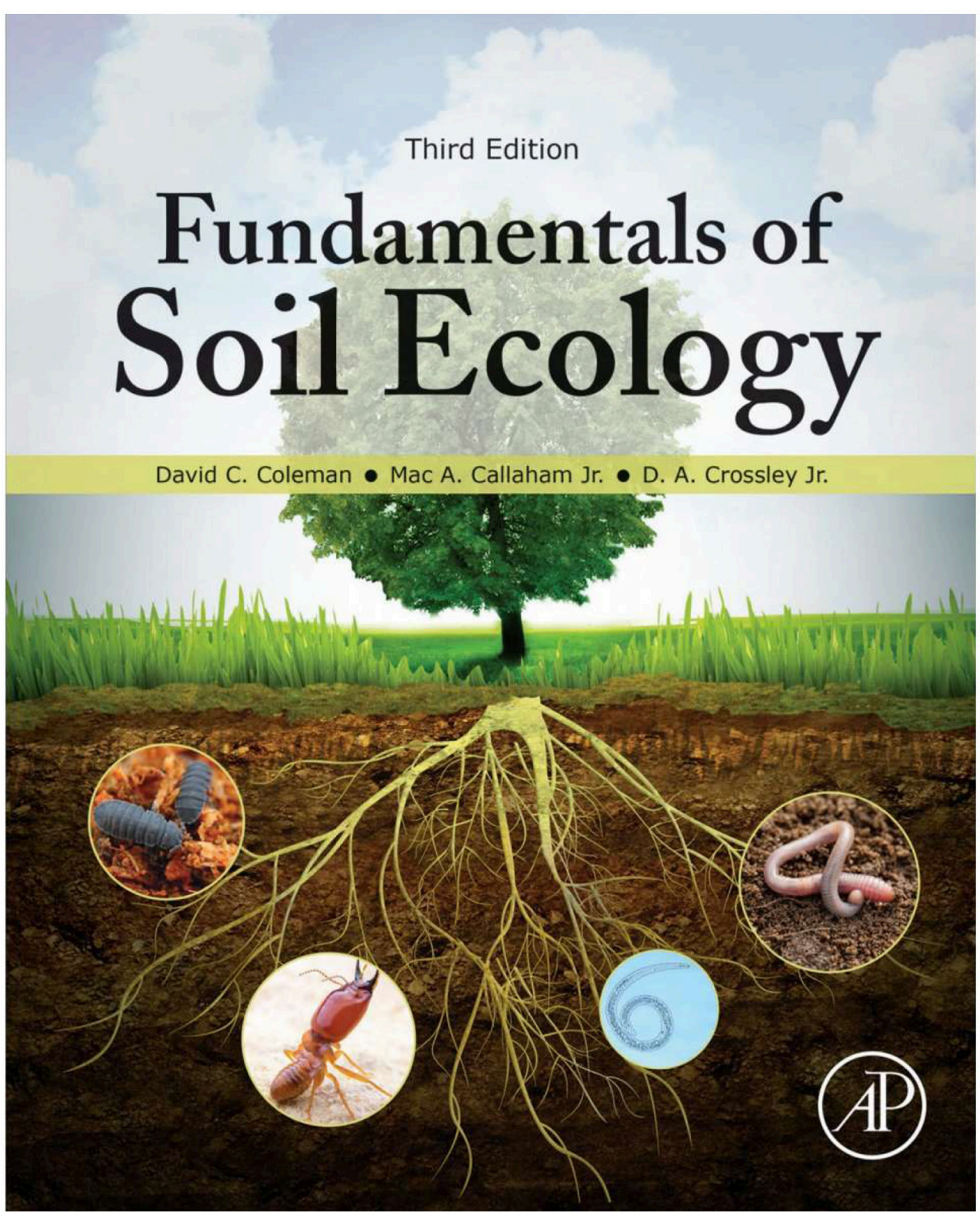

FIGURE 1 | Book cover of Fundamentals of Soil Ecology (Reprinted with permission of Elsevier, holder of copyright). 
of the book has been greatly expanded to include groups that were not considered previously (e.g., protozoa and mycorrhizae) and the information presented is better structured into thematic sections (i.e., root-, microbial-, or process-related studies). The descriptions of the different exercises include list of materials needed, step by step descriptions of sampling and processing protocols, recommendations for transportation and preservation (including recipes for clearing and mounting specimens onto microscope slides), and cautionary comments. The instructions provided are very easy to follow and are suitable for selfdirected learning, allowing non-experienced students to perform ecological studies.

However, it would have been useful to include other basic methodologies to describe soil profiles (soil color, identification of the soil horizons), soil structure (aggregate size classifications), soil texture, and some physical (water content), and chemical properties (soil $\mathrm{pH}$ ). Regarding the soil faunal exercises, the authors have covered the whole range of microfauna (nematodes), mesofauna (microarthropods and enchytraeids), and macrofauna (macroarthropods and earthworms), but the collection of many of these organisms often requires specialized equipment (Baermann and Berlese funnels), whereas there are other soil fauna groups that can be more easily targeted, such as tardigrades (Shaw, 2014).

Nevertheless, in spite of these very slight shortcomings, soil ecology, as stated earlier, is about interactions between the abiotic and biotic components of the soil system and therefore, the book section on "process-related exercises" is extremely valuable, in that it provides potential readers with good examples of easy procedures to see soil biology into action! Soil respiration reflects the metabolic activity of the soil, and litter decomposition studies can inform us about the quality of the organic matter produced

\section{REFERENCES}

Benson, J. L. (2000). Greek Color Theory and the Four Elements: A Cosmological Interpretation. University of Massachusetts: Amherst Libraries. Available online at: https://scholarworks.umass.edu/art_jbgc/1

Briones, M. J. I. (2014). Soil fauna and soil functions: a jigsaw puzzle. Front. Environ. Sci. 2:7. doi: 10.3389/fenvs.2014.00007

Coleman, D., Callaham, M., and Crossley, D. Jr. (2017). Fundamentals of Soil Ecology, (3rd Edn). London: Academic Press.

Cotrufo, M. F., Del Galdo, I., and Piermatteo, D. (2010). "Litter decomposition: Concepts, methods and future perspectives," in Soil Carbon Dynamics. An Integrated Methodology, eds L. K. Werner, M. Bahn, and A. Heinemeyer (New York, NY: Cambridge University Press), 76-90.

Frouz, J., Roubickova, A., Hedenec, P., and Tajovsky, K. (2015). Do soil fauna really hasten litter decomposition? A meta-analysis of enclosure studies. Eur. J. Soil Biol. 68, 18-24. doi: 10.1016/j.ejsobi.2015.03.002

Hawksworth, D. L., and Lücking, R. (2017). Fungal diversity revisited: 2.2 to 3.8 million species. Microbiol. Spectr. 5:FUNK-0052-2016. doi: 10.1128/microbiolspec.FUNK-0052-2016 by the primary producers. In addition, by constructing litter bags of different mesh sizes to selectively include/exclude fauna (or their different sized groups, micro-, meso-, or macro-fauna) the researchers can also quantify the contributions of the different soil organisms to the decay rates and their dynamics (e.g., Frouz et al., 2015).

In summary, the book by Coleman, Callaham and Crossley allow us not only to get a good grasp of the complexity of soil ecology studies but also to encourage young researchers and teachers to deepen their knowledge through fun exercises. The book also makes a very positive connection between soil ecology and the preservation of a healthy Planet for future generations, a mandate for our generation, on which one can never insist too much. The prohibitively high price of the book ( $\$ 99.95$ both for the paperback and ebook versions) poses a financial barrier to prospective buyers, and, sadly, in particular to students, but hopefully University libraries will be able to support would-be soil ecologists by getting an Institutional subscription to the e-book. This will enable a wide audience to gain access to this high-quality book, which is very much worth reading since it provides the most comprehensive current state-of-the-art on the central role of soils in the functioning of terrestrial ecosystems.

\section{AUTHOR CONTRIBUTIONS}

The author confirms being the sole contributor of this work and approved it for publication.

\section{ACKNOWLEDGMENTS}

I am very grateful to the Editor in Chief for their useful comments to improve the writing style of this review.

Jenny, H. (1941). Factors of Soil Formation. New York, NY: McGraw-Hill.

Shaw, M. (2014). Kids \& Teachers Tardigrade Science Project Book: How To Find Tardigrades and Observe Them Through a Microscope. Scotts Valley, CA: CreateSpace Independent Publishing Platform.

Wardle, D. A., Bardgett, R. D., Klironomos, J. K., Setälä, H., van der Putten, W. H., and Wall, D. H. (2004). Ecological linkages between aboveground and belowground biota. Science 304, 1629-1633. doi: 10.1126/science. 1094875

Conflict of Interest Statement: The author declares that the research was conducted in the absence of any commercial or financial relationships that could be construed as a potential conflict of interest.

Copyright (C) 2018 Briones. This is an open-access article distributed under the terms of the Creative Commons Attribution License (CC BY). The use, distribution or reproduction in other forums is permitted, provided the original author $(s)$ and the copyright owner(s) are credited and that the original publication in this journal is cited, in accordance with accepted academic practice. No use, distribution or reproduction is permitted which does not comply with these terms. 